\title{
ANALISIS SIFAT FISIK DAN MEKANIK SAMBUNGAN LAS OXY-ACETYLENE PADA PELAT BAJA KARBON RENDAH DENGAN VARIABEL NYALA TORCH KARBURASI
}

\author{
Andika Wisnujati ${ }^{1}$, Ahmad Nurhuda ${ }^{2}$ \\ ${ }^{1 \& 2}$ Prodi D3 Teknik Mesin Universitas Muhammadiyah Yogyakarta \\ ${ }^{1)}$ Email: awjati83@gmail.com \\ Jl. Lingkar Selatan, Tamantirto, Kasihan, Bantul, D.I.Yogyakarta
}

\begin{abstract}
Oxy-acetylene welding is widely used in small workshops for car body repair, automobile and motorcycle exhaust, and other improvements using a maximum temperature of $3000^{\circ} \mathrm{C}$ that can not be done through another process. The purpose of this study was to analyze the effect of torque oxyacetylene flame carburizing on the physical-mechanical properties of low carbon steel plate welding joints.

The method employed by using a low carbon steel plate 2 (two) pairs in a butt weld dimmension of $300 \mathrm{~mm} \times 75 \mathrm{~mm} \times 1 \mathrm{~mm}$. After welding with oxy-acetylene in torch carburizing flame, the specimens were examined through physical observation including microstructure and mechanical properties. Micro hardness vickers (VHN) was used to evaluate the harness and tensile properties was determine using the universal testing machine.

In the microstructure testing, there is a pearlite and ferrite whose become different dimensions as it is affected by the heat and air pressure of the weld. The result of tensile strength specimen A 174,6 $\mathrm{N} / \mathrm{mm}^{2}$ and specimen $B \quad 157,65 \mathrm{~N} / \mathrm{mm}^{2}$. While the vickers test obtained the highest hardness that is $152.5 \mathrm{VHN}$ in the welding area.
\end{abstract}

Keywords: Oxy Acetylene, Carburizing Flame, Low Carbon Steel, Physical and mechanical properties.

\section{PENDAhuluan}

Pengelasan merupakan bagian tak terpisahkan dari pertumbuhan peringatan industri karena memegang peranan utama dalam rekayasa dan reparasi produksi logam dan besi. Hampir tidak mungkin pembangunan suatu pabrik tanpa melibatkan unsur pengelasan. Pada era industri teknik pengelasan telah banyak dipergunakan secara luas pada penyambungan batang-batang pada konstruksi bangunan baja dan konstruksi mesin. Luasnya pengguanaan teknologi ini disebabkan karena bangunan dan mesin yang dibuat dengan teknik penyambungan menjadi ringan dan lebih sederhana dalam prosesnya.

Las Oxy-acetylene adalah proses pengelasan secara manual, dimana permukaan yang akan disambung mengalami pemanasan sampai mencair oleh nyala (flame) gas acetylene yaitu pembakaran $\mathrm{C}_{2} \mathrm{H}_{2}$ dengan $\mathrm{O}_{2}$ dengan logam pengisi atau tanpa logam pengisi dimana prosess penyambungan tanpa penekanan. Disamping untuk keperluan pengelasan (penyambungan) las oxy-acetylene dapat juga digunakan sebagai preheatting, brazing, cutting dan hard facing. Penggunaan untuk produksi (production welding), pekerjaan lapangan (field work), dan reparasi (repair \& maintenance). Dalam aplikasi hasilnya sangat memuaskan untuk pengelasan baja karbon, terutama lembaran logam (sheet metaal) dan pipa-pipa berdinding tipis. Meskipun hampir semua jenis logam ferrous dan non ferrous dapat di las dengan las gas, baik dengan atau tanpa bahan tambahan (filler metal).

Penelitian ini dilakukan untuk mengetahui perubahan sifat fisik yang terjadi pada plat baja karbon rendah setelah di las dengan menggunakan las oxy acetylene dengan nyala torch karburasi pada daerah las, HAZ (Heat Affected Zone) dan induk dilihat dari struktur mikronya, pengaruh pengelasan dengan menggunakan las oxy acetylene dengan nyala torch karburasi terhadap uji tarik dan uji kekerasan mikro vickers (VHN). 


\section{LANDASAN TEORI}

Peralatan utama las oxy-acetylene adalah apioxy-acetylene sehingga las ini sering disebut las api. Kualitas api sangat berpengaruh terhadap lasan. Secara teorotis, pembakaran sempurna acetylene berlangsung menurut reaksi kimia sebagai berikut ;

$\mathrm{C}_{2} \mathrm{H}_{2}+2,5 \mathrm{O}_{2} \longrightarrow 2 \mathrm{CO}_{2}+\mathrm{H}_{2} \mathrm{O}$

Dari persamaan reaksi tersebut diketahui bahwa satu volume acetylene memerlukan 2,5 volume oksigen menghasilkan dua volume carbon dioksida dan satu volume zat air (uap air).

Dalam kenyataan reaksi tersebut tidak berlangsung sekali tetapi dua tahap. Tahap pertama (reaksi primair) terjadi nyala inti dengan persamaan raksi.

$\mathrm{C}_{2} \mathrm{H}_{2}+\mathrm{O}_{2} \longrightarrow 2 \mathrm{CO}+\mathrm{H}_{2}$

Berdasarkan persamaan tersebut diketahui bahwa satu volume acetylene memerlukan hanya satu volume oksigen. Oksigen ini diperoleh dari tabung oksigen hasil reaksi primair adalah dua volume carbon monokside dan satu volume hydrogen serta panas diperoleh dari penguraian acetylene dan oksidasi carbon yang berasal dari acetylene yang terurai.

Nyala inti tersebut relatif kecil, bersinar terang berwarna kebiru-biruan. Nyala inti inilah yang menghasilkan panas cukup tinggi yang diperlukan untuk pengelasan. Jika semua carbon yang terurai pada tahap pertama habis terbakar pada tahap itu pula maka api dikatakan api netral. Tidak ada unsur carbon yang lepas dan bereaksi dengan benda kerja.

Reaksi kedua terjadi diluar kelopak nyala inti. Pada tahap kedua ini carbonmonoksida dan hydrogen hasil reaksi tahap pertama terbakar oleh oksigen dari udara bebas menghasilkan carbon dioksida dan uap air seperti persamaan reaksi berikut :

$2 \mathrm{CO}+3 / 4 \mathrm{H}_{2}+1,5 \mathrm{O}_{2} \longrightarrow 2 \mathrm{CO}_{2}$ $+\mathrm{H}_{2} \mathrm{O}$

Panas yang dihasilkan dari reaksi panas kedua ini sebenarnya lebih besar dari tahap pertama, namun karena kecepatan pembakaran rendah dibanding suhu pada nyala inti. Sebaliknya, nyala inti kecil tetapi kecepatan pembakaran jauh lebih tinggi, karena suplay oksigen murni dari botol yang bertekanan sehingga suhu lebih tinggi.

Nyala apioxy-acetylene bisa dikontrol dengan mudah memakai katub yang ada pada pembakaran. Perubahan proporsi campuran oksigen dan acetylene yang mengalir keujung pembakaran akan merubah karakteristik kimiawi nyala inti yang akan mempengaruhi pencairan dan komposisi benda kerja. Nyala hasil pembakaran dalam las oxy-acetylene dapat berubah tergantung dari perbandingan antara gas oksigen dan gas acetylene ditunjukkan pada gambar dibawah ini:

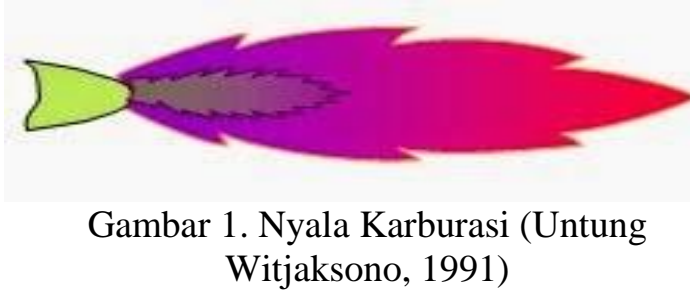

Proses pengelasan las oxy-acetylene sering di dapatkan suatu cacat pada las oxy acetylene diantaranya adalah penetrasi yang kurang sempurna, fusi yang kurang sempurna, undercutting, porosity dan longitudinal crack. Pengelasan oxy acetylene masih banyak digunakan di bengkel-bengkel kecil untuk proses repair karoseri mobil, kenalpot mobil dan motor yang menggunakan suhu $3000^{\circ} \mathrm{C}$ yang tidak bisa dilakukan dengan proses lain. (Handar dan Yudi, 2011)

Penelitian yang dilakukan oleh Wilopo, dkk (2013) tentang studi kualitas repair welding menggunakan metode oxy acetylene dengan PWHT pada cast wheel alumunium didapatkan hasil struktur mikro daereh logam las yang pada waktu pengelasan mencair dan membeku terdiri dari komponen logam induk dan bahan tambahan elektroda. Kekuatan yang diuji kekerasan mengalami penurunan dari material raw $0,0924 \mathrm{~J} / \mathrm{mm}^{2}$ sedangkan pada daerah las $0,0789 \mathrm{~J} / \mathrm{mm}^{2}$. Handar dan Yudi 
(2011) tentang studi kekuatan las oxy acetylene pada variasi kampuh didapatkan hasil kekuatan tarik hasil pengelasan padasambungan dengan kampuh $\mathrm{V}$ yaitu sebesar $317,7 \mathrm{~N} / \mathrm{mm}^{2}$ sedangkan kekuatan terkecil terjadi pada sambungan las dengan kampuh U yaitu sebesar $268.3 \mathrm{~N} / \mathrm{mm}^{2}$.

\section{METODE PENELITIAN}

\section{A. Alat Penelitian}

Penelitian ini menggunakan pelat baja karbon rendah berukuran $300 \mathrm{~mm}$ x 75 $\mathrm{mm} \times 1 \mathrm{~mm}$ berjumlah 6 pasang. Jumlah tersebut, 3 (tiga) pasang untuk pengujian kekerasan dan 3 (tiga) pasang untuk pengujian tarik. Enam pasang potongan pelat di las oksi-asetelin dengan varibel nyala karburasi. Batang las menggunakan R60 (ASME, 2001). Pada pengelasan oxyacetylene dengan nyala apikarburasi terhadap baja karbon rendah menggunakan beberapa alat penunjang yang berkaitan dengan proses pengelasan, diantaranya: Sikat kawat (wire brush), palu Las (chipping hammer), tang jepit, mesin gerinda tangan, alat pelindung diri.
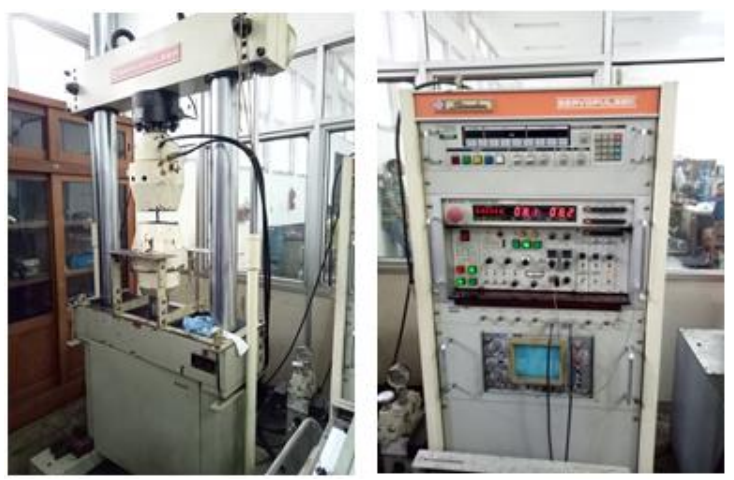

Gambar 2. Alat Uji Tarik Servopulser

\section{B. Bahan Penelitian}

Bahan yang digunakan dalam penelitian ini adalah: las oxy-asetilen, dan pelat baja karbon rendah.

\section{Tempat Penelitian}

Pelaksanaan pembuatan bahan (specimen) pengecoran dilakukan di laboratorium proses produksi D3 Teknik Mesin, Universitas Muhammadiyah
Yogyakarta. Pengujian bahan dilakukan di laboratorium bahan, Departemen Teknik Mesin dan Industri Fakultas Teknik, Universitas Gadjah Mada Yogyakarta. Deskripsi pengujian tarik dibuat tabel dan grafik untuk distribusi fase ferit atau perlit dan ukuran butir pada struktur mikro, dan distribusi kekerasan mikro Vickers daerah logam induk (base metal), daerah terpengaruh panas (heat affected zone), dan logam las (welding metal).

\section{Metode Pengujian}

Persiapan yang dilakukan sebelum mengamati struktur mikro adalah pengefraisan spesimen, pengampelasan, pemolesan dan pengetsaan. Setelah dipilih, bahan uji diratakan kedua permukaannya dengan menggunakan mesin frais, dalam pendinginan harus selalu terjaga agar tidak timbul panas yang mempengaruhi struktur mikro. Setelah rata digosok dengan menggunakan ampelas mulai dari yang kasar sampai yang halus. Arah pengampelasan setiap tahap harus diubah, pengampelasan yang lama dan penuh kecermatan akan menghasilkan permukaan yang halus dan rata. Bahan yang halus dan rata itu diberi penghalus autosol untuk membersihkan noda yang menempel pada bahan. Langkah terakhir sebelum dilihat struktur mikro adalah dengan mencelupkan spesimen kedalam larutan etsa dengan penjepit tahan karat dan permukaan menghadap keatas. Kemudian spesimen dicuci dengan air, dikeringkan dan dilihat stuktur mikronya dengan mikroskop.

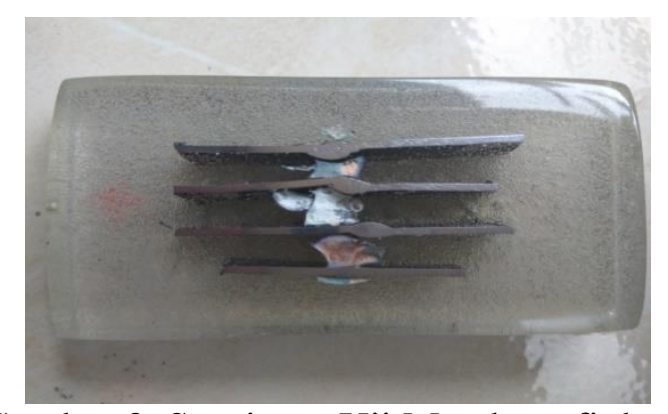

Gambar 3. Spesimen Uji Metalografi dan kekerasan mikro vickers

IV. HASIL DAN PEMBAHASAN 


\section{A. Hasil Penelitian}

Setelah dilakukan penelitian tentang perubahan sifat fisik yang terjadi pada plat baja karbon rendah setelah di las dengan menggunakan las oxy acetylene dengan nyala torch karburasi pada daerah las, HAZ (Heat Affected Zone) dan logam induk, maka didapatkan hasil sebagai berikut :

\section{1) Data Spesimen Uji Metalografi}

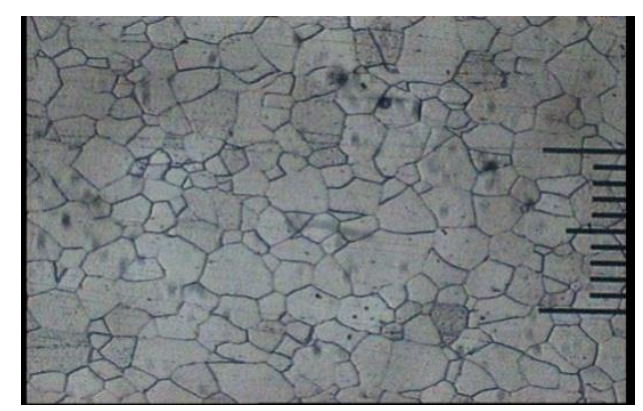

Gambar 4. Struktur mikro raw material

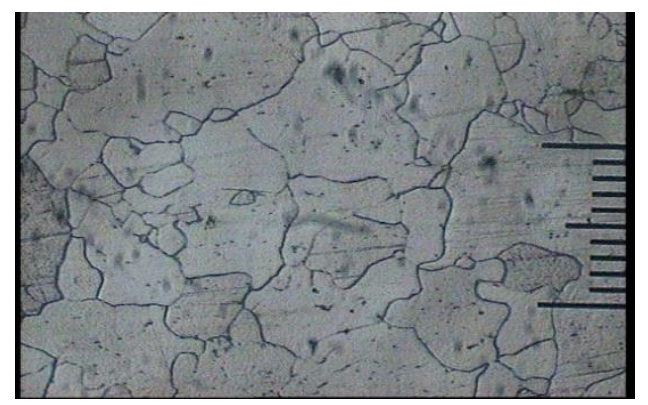

Gambar 5. Struktur mikro daerah HAZ

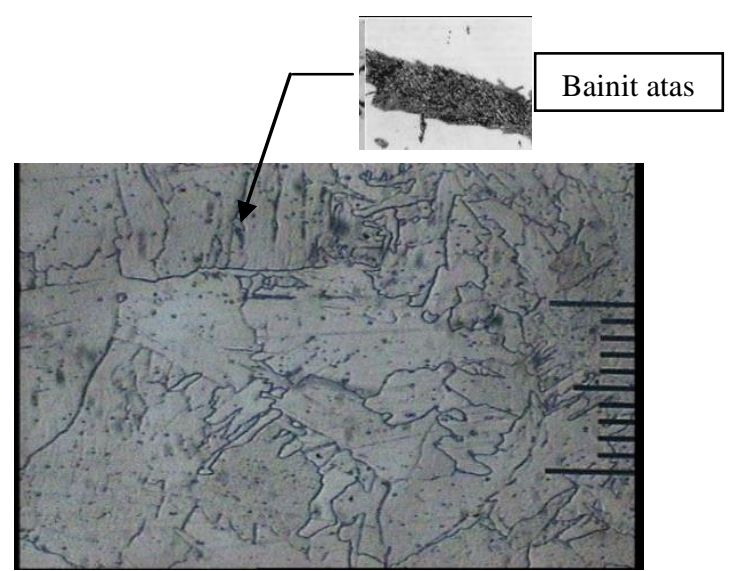

Gambar 6. Struktur mikro daerah Las

\section{2) Data Spesimen Pengujian Kekerasan}

\begin{tabular}{|c|c|c|c|c|}
\hline \multicolumn{5}{|c|}{ Tabel 1. Hasil Uji Kekerasan N } \\
\hline 1 & \multirow{3}{*}{ Las } & 48,5 & 157,7 & 152,5 \\
\hline 2 & & 50,5 & 145,4 & 152,5 \\
\hline 3 & & 49,0 & 154,5 & 152,5 \\
\hline 4 & \multirow{3}{*}{ Haz } & 51,5 & 139,8 & 137,13 \\
\hline 5 & & 52,5 & 134,6 & 137,13 \\
\hline 6 & & 52,0 & 137,2 & 137,13 \\
\hline 7 & \multirow{3}{*}{ Raw } & 48,5 & 127,2 & 128 \\
\hline 8 & & 46,0 & 127,2 & 128 \\
\hline 9 & & 47,5 & 129,6 & 128 \\
\hline
\end{tabular}

Hasil pengujian kekerasan vickers dilakukan menggunakan beban 200gf. Adapun hasilnya sebagai berikut:

Grafik hasil uji kekerasan di sajikan Gambar 7 sebagai berikut:

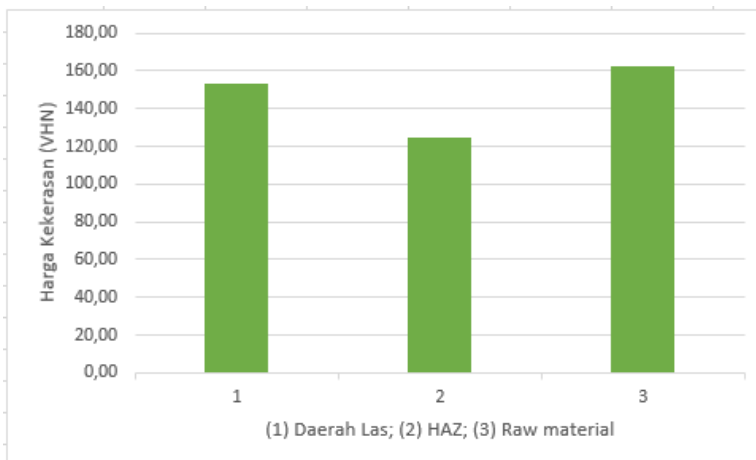

Gambar 7. Grafik Uji Kekerasan

\section{3) Data Hasil Pengujian Tarik}

Setelah dilakukan pengujian tarik, didapatkan hasil sesuai Tabel 2 sebagai berikut:

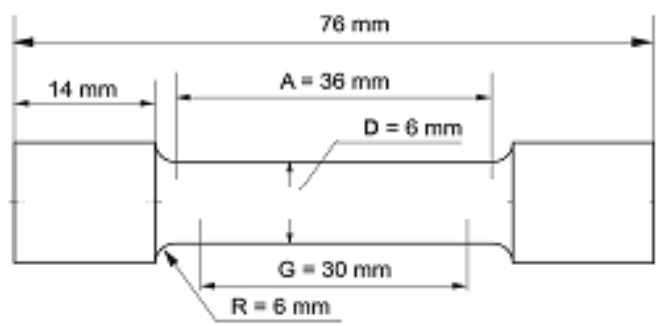


Gambar 7. Spesimen uji tarik (Standar JIS Z 2201)

Tabel 2. Hasil Uji Tarik

\begin{tabular}{|c|c|c|c|c|c|c|}
\hline $\begin{array}{c}\text { Kode } \\
\text { spesi } \\
\text { men }\end{array}$ & $\begin{array}{c}\text { Lo } \\
(\mathrm{mm} \\
)\end{array}$ & $\begin{array}{c}\mathrm{Li} \\
(\mathrm{mm} \\
)\end{array}$ & $\begin{array}{c}p \text { ma } \\
\mathrm{x} \\
(\mathrm{kg})\end{array}$ & $\begin{array}{c}\sigma \mathrm{max} \\
(\mathrm{N} / \mathrm{mm} \\
2\end{array}$ & $\begin{array}{c}\sigma y i l d \\
\left(\mathrm{~N} / \mathrm{mm}^{2}\right)\end{array}$ & $\begin{array}{c}\mathrm{e} \\
(\%)\end{array}$ \\
\hline A & 50 & 6,1 & 214 & 174,76 & 142,1 & 22 \\
\hline B & 50 & 6,4 & 206 & 157,65 & 152 & 28 \\
\hline
\end{tabular}

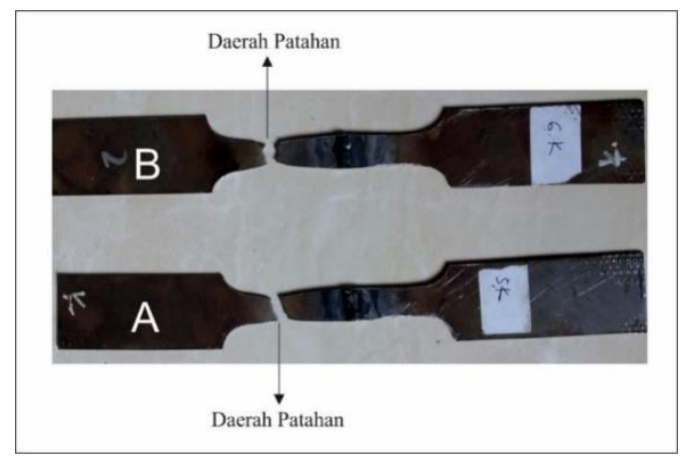

Gambar 8. Patahan Hasil Uji Tarik

\section{B. Pembahasan}

Setelah dilakukan pengujian struktur mikro Hasil pengujian baja karbon rendah yang telah di las oleh las oxy-acetylene dengan variabel nyala torch karburasi pada daerah las bisa dilihat pada gambar 6 . Daerah logam las adalah bagian dari logam yang pada waktu pengelasan mencair dan kemudian membeku. Komposisi logam las terdiri dari komponen logam induk dan bahan tambah dari elektroda. Karena logam las dalam proses pengelasan ini mencair kemudian membeku, maka kemungkinan besar terjadi pemisahan komponen yang menyebabkan terjadinya struktur yang tidak homogen, ketidakhomogennya struktur akan menimbulkan struktur ferit kasar dan bainit atas yang menurunkan ketangguhan logam las. Pada daerah ini struktur mikro yang terjadi adalah struktur cor. Struktur mikro di logam las dicirikan dengan adanya struktur berbutir panjang (columnar grains). Struktur ini berawal dari logam induk dan tumbuh ke arah tengah daerah logam las kandungan masih.

Pada daerah HAZ yang dekat pada garis lebur ferrite akan mengalami pertumbuhan dengan cepet pada proses pengelasan berlangsung sehingga struktur berubah sesuai dengan siklus thermal yang terjadi saat pengelasan dilakukan, sehingga menyebabkan daerah HAZ terjadi penurunan kekuatan yang mengakibatkan menjadi daeah yang rawan getas. Daerah pengaruh panas atau $H A Z$ adalah logam dasar yang bersebelahan dengan logam las yang selama proses pengelasan mengalami siklus thermal pemanasan dan pendinginan cepat. Retak dingin tidak hanya terjadi pada daerah HAZ (Heat Affected Zone) atau sering disebut dengan daerah pergaruh panas tetapi biasanya terjadi pada logam las. Retak dingin ini dapat terjadi pada daerah panas yang sering terjadi. Dan retakan ini dapat dilihat dibawah manik Ias, retak akar dan kaki, serta retak melintang. Namun cacat las tersebut tidak menjadi bagian dari penelitian ini.

Pembebanan tarik adalah pembebanan yang diberikan pada benda dengan memberikan gaya tarik berlawanan arah pada salah satu ujung benda. Penarikan gaya terhadap beban akan mengakibatkan terjadinya perubahan bentuk (deformasi) bahan tersebut. Proses terjadinya deformasi pada bahan uji adalah proses pergeseran butiran kristal logam yang mengakibatkan melemahnya gaya elektromagnetik setiap atom logam hingga terlepas ikatan tersebut oleh penarikan gaya maksimum. Pada pengujian tarik beban diberikan secara kontinu dan perlahan bertambah besar, bersamaan dengan itu dilakukan pengamatan mengenai perpanjangan yang dialami benda uji dan dihasilkan kurva teganganregangan. (Wisnujati, 2017).

Dari hasil pengujian tarik pada sambungan las oxy acetylene dangan variabel nyala torch karburasi terhadap baja karbon rendah memiliki tegangan tarik spesimen A sebesar 174,76N/mm² 
dan spesimen B sebesar 157,65N/mm² sedangkan tegangan luluh spesimen $\mathrm{A}$ sebesar $142,1 N / \mathrm{mm}^{2}$ dan spesimen B sebesar $116,4 N / \mathrm{mm}^{2}$.
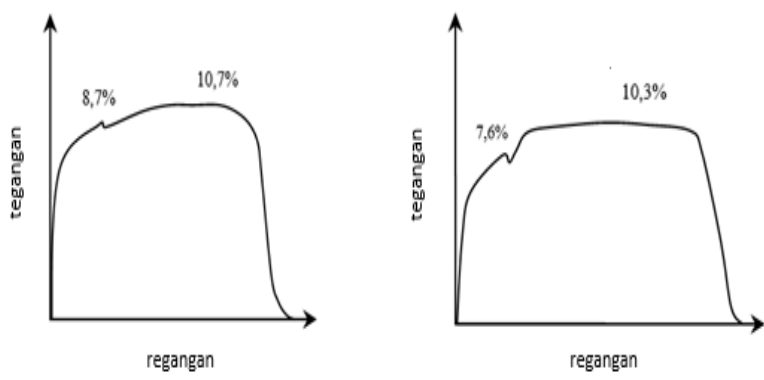

Gambar 9. Grafik Hasil Uji Tarik

Dimana dari hasil pengujian kekerasan Vickers (VHN) pada baja karbon rendah yang dapat perlakukan pengelasan oxy acetylene dengan nyala torch karburasi memperlihatkan nilai rata-rata kekerasan pada daerah las pada titik 1-3 yaitu sebesar 152,5 VHN. Kemudian pada daerah Pada titik 4-6 yaitu pada daerah HAZ memperlihatkan rata-rata nilai kekerasan sebesar 136,2 VHN. Sedangkan pada daerah induk pada titik 7-9 menunjukan nilai kekerasan rata-rata sebesar 128 VHN.

Perbandingan ini bertujuan untuk mengetahui kekuatan yang paling kuat dari setiap titik yang di uji kekerasan Vickers (VHN). Hasil dari pengujian diambil tiap daerah satu titik yaitu : daerah Las, daerah HAZ dan daerah Induk. Dari data diatas terlihat bahwa nilai kekerasan tertinggi terdapat pada daerah las dengan nilai 152,5 VHN. Sedangkan nilai kekerasan terendah terdapat pada daerah induk dengan nilai sebesar 116,2 128 VHN.

\section{KESIMPULAN}

Dari hasil penelitian diatas didapatkan kesimpulan sebagai berikut:
1) Hasil pengujian struktur mikro perbesaran 100x pada pengelasan oksi asetilen dengan nyala tocrh karburasi terhadap baja karbon rendah. Dari data diatas dapat disimpulkan bahwa panas mempengaruhi ukuran ferit dan perlit dan tekanan yang dihasilkan oleh las mempengaruhi rapih atau tidaknya struktur ferlit dan perlit.

2) Nilai kekerasan tertinggi terdapat pada daerah las untuk nilai rata-rata sebesar 152,5 VHN dan nilai kekerasan terendah terletak pada daerah induk untuk nilai rata-rata 128 VHN dimana pada proses uji tarik terlihat bahwa apabila daerah kekerasan nya rendah maka akan mudah patah.

3) Pengujian tarik pada baja karbon rendah dengan pengelasan nyala api karburasi pada spesimen A memiliki nilai lebih tinggi dibanding spesimen B nilainya sebesar $174,76 \mathrm{~N} / \mathrm{mm}^{2}$ untuk tegangan tarik dan 142,1 $\mathrm{N} / \mathrm{mm}^{2}$ untuk nilai tengangan luluh. Sedangkan untuk nilai spesimen B $157,65 \mathrm{~N} / \mathrm{mm}^{2}$ untuk tegangan tarik dan $116,4 \mathrm{~N} / \mathrm{mm}^{2}$ untuk nilai tengangan luluh.

\section{DAFTAR PUSTAKA}

Handar, N dan Yudi, P. I(2011).,Studi Kekuatan Las Oxy Acetylene pada Variasi KampuhJurnal Teknik Mesin Vol. 1, No. 1, Oktober 2011: 1-8. Institut Teknologi Padang.

JIS Handbook Non Ferrous Metal and Metallurgy, 1977, Japanese Standards Association

Surdia, Tata, dkk.(1999)., Pengetahuan Bahan Teknik, Edisi 4, PT. Pradya Paramita, Jakarta

Wilopo Irman A, dkk.(2013)., Studi Kualitas repair welding menggunakan metode oxy acetylene dengan PWHT pada cast wheel alumunium. Universitas Negeri Yogyakarta 
Wisnujati, A. (2017). Analisis Perlakuan Carburizing terhadap Sifat Fisik dan Mekanik pada Bahan Sprocket Sepeda Motor. Jurnal Simetris Universitas Muria Kudus. 